\title{
Evaluation of the Application Benefit of Meteorological High Performance Computing Resources
}

\author{
Min Wei, Bin Wang* \\ National Meteorological Information Center, Beijing, China \\ Email: *wangbin@cma.gov.cn
}

How to cite this paper: Wei, M. and Wang, B. (2017) Evaluation of the Application Benefit of Meteorological High Performance Computing Resources. Journal of Geoscience and Environment Protection, 5, 153-160.

https://doi.org/10.4236/gep.2017.57012

Received: April 12, 2017

Accepted: July 18, 2017

Published: July 21, 2017

Copyright (c) 2017 by authors and Scientific Research Publishing Inc. This work is licensed under the Creative Commons Attribution International License (CC BY 4.0).

http://creativecommons.org/licenses/by/4.0/

\begin{abstract}
The meteorological high-performance computing resource is the support platform for the weather forecast and climate prediction numerical model operation. The scientific and objective method to evaluate the application of meteorological high-performance computing resources can not only provide reference for the optimization of active resources, but also provide a quantitative basis for future resource construction and planning. In this paper, the concept of the utility value $\mathrm{B}$ and index compliance rate $\mathrm{E}$ of the meteorological high performance computing system are presented. The evaluation process, evaluation index and calculation method of the high performance computing resource application benefits are introduced.
\end{abstract}

\section{Keywords}

High-Performance Computing Resources, Resource Application, Benefit Evaluation, Benefit Value

\section{Introduction}

The application benefit evaluation of meteorological high-performance computing resource is an important basis for the decision-making of high-performance computing capability of meteorological department. It is also the basis for improving the service of computing resource and the rational use of computing resource. However, because the computing resources involve many levels, the diversification of the benefit manifestation makes the assessment work difficult to measure and uncertainty. The related research of the domain evaluates and analyzes the resource utilization of specific level and specific index from different aspects, such as system performance evaluation [1], application performance tuning, and job scheduling capability optimization [2] [3]. There is no unified, 
objective, quantitative assessment of the effectiveness of resource applications and evaluation models. In this paper, the overall calculation of resources will be taken into account, extracting the key indicators at all levels, adopting the way of the use of expert assessment and objective measurement method of combining, and conducting a quantitative assessment of the effectiveness of the application of resources. The scientific and accurate analysis and evaluation of the application efficiency of active computing resources can not only promote the optimal use of active resources, improving the effective utilization of resources, but also for the future resource construction and resource management allocation to provide a reference basis for quantification.

\section{Application of Meteorological High Performance Computing Resources}

Meteorological high-performance computing resources includes high-performance computer hardware infrastructure and resource management and application software environment. The high performance computer is the hardware support platform for the numerical model operation. The resource management and application soft environment is the software service environment in which the numerical model runs.

Meteorological high-performance computing resources are an indispensable technical support for the development of numerical models. At present, the major meteorological numerical model business applications include the GRAPES (Global and Regional Assimilation and Prediction System) weather model [4] [5] and the BCC_CSM (Beijing Climate Center Climate System Model) [6] [7] independently developed by our country. GRAPES global model horizontal resolution of $25 \mathrm{~km}$, vertical 60 layers, the level of resolution in 2020 to $10 \mathrm{~km}$ encrypted resolution, the vertical level increased to 90 . The BCC_CSCM model is a climate system model consisting of four components: atmosphere, ocean, land and sea ice. Its atmospheric component model BCC_AGCM (Beijing Climate Center Atmospheric General Circulation Model) has a horizontal resolution of about $50 \mathrm{~km}$ and a vertical 26 layers, and is scheduled to be encrypted to $30 \mathrm{~km}$, the vertical layer number increased to 70 . With the numerical model in terms of time, scope, etc. more accurate, in time and space resolution, update frequency and so on more sophisticated development, the demand for computing resource capacity is growing. The demand for computing resource quality of service (including services such as parallel computing, application support software, etc.) is increasing [8] [9]. The goal of computing resources construction, from the initial simple focus on capacity-building, transition to both the ability and quality of service stage. The management of computing resources is shifted from the initial coarse-grained local allocation to the fine-grained global sharing deployment phase [10] [11].

At present, the meteorological industry, high-performance computing resources mainly in the national, regional deployment, include IBM Flex P460 and other systems. Although the geographical distribution is different, but logically unified into the pool of computing resources, can be pre-allocated pool of re- 
sources for unified scheduling for the national and regional numerical model business, scientific research work to provide technical services (In accordance with the known application requirements and resource supply capacity, pre-selected system ready in the data environment, to achieve the application of resource scheduling operation). To achieve the system computing and storage resource usage, the main application of the resource occupancy will be monitored and evaluated. Carrying out some technical researches [12] [13] of parallel algorithm optimization, heterogeneous parallel acceleration and so on. But overall, the soft power of application is still relatively weak, to be further strengthened.

\section{Assessment of Significance and Methods}

\subsection{Significance of Assessment}

The demand of computing resources is increasing and the scale of resource construction is increasing. The application of active computing resources is to carry out scientific and accurate analysis and evaluation. On the one hand, it can promote the optimized use of active resources, make the system function more perfect, balanced performance, can be efficient and stable continuous operation, improve the efficiency of resource utilization. On the other hand, it can provide quantitative reference for future resource construction and resource management allocation. At the same time, the introduction of the energy efficiency of the output assessment, can promote the efficient use of energy to achieve the goal of green energy.

\subsection{Evaluation Methods}

At present, the application of meteorological high-performance computing resource evaluation mainly adopts experts' evaluative and objective measurement method.

Expert evaluation method is a kind of expert judgment, interactive evaluation method. The main users of high-performance computing resources are divided into business class, major task class, scientific research category and several other categories, and use satisfaction, ease of use of resources, and relying on highperformance computing resources obtained by the application of industry content and other research content will be investigated for national and regional users of high-performance computing resource respectively. According to the research results, there is a subjective assessment of the effectiveness the application of high-performance computing resources. Expert evaluation method can be closely integrated with the specific circumstances of the evaluation, so that the evaluation has a strong targeted.

Objective measurement algorithm is an objective and quantitative measurement of the use of high-performance computing resources, model computing efficiency and infrastructure support for supporting computing resources [14]. According to the measurement results, the application of high-performance computing resources will be assessed objectively. Objective measurement algorithm is relatively fixed, operable and easy to use. 


\section{The Initial Establishment of the Evaluation System}

\subsection{Evaluation Process}

At this stage, the majority of meteorological departments provide high-performance computing resources for users in the field free of charge. In order to carry out comprehensive assessment of the application of resources and provide a clear quantitative indicator, the application value B of meteorological highperformance computing resource will be established. According to the multivariate characteristics of computing resources, the assessment index of grading is determined, and the corresponding calculation method of utility value is set up for each evaluation index, and the comprehensive benefit value is obtained after the aggregation, which forms the evaluation system of application efficiency of meteorological high performance computing resources [15]. As shown in Figure 1.

\subsection{Assessment Indicators}

The level of computing resources, for example, CPU cycles and memory, required by various computing tasks greatly varies depending upon the nature of the task. For example, word processing tasks can generally be run on a microcomputer that is dedicated to a particular person. Simulation tasks such as those for simulating the operation of a circuit, on the other hand, generally require relatively large levels of computing resources. Thus, simulation tasks are often performed on systems other than the microcomputers. Meteorological highperformance computing resources are hierarchical, including, high-performance computer hardware, system software and application software. As the fundamental driving force of high performance computing system, energy is the bottom layer of high performance computing resources, as shown in Figure 2.

Aiming at the complexity of high-performance computing resource application, a three-level evaluation index is established. The first indicators are for the use of high-performance computer overall efficiency. The secondary level index include the overall service satisfaction, infrastructure benefits, resource usage

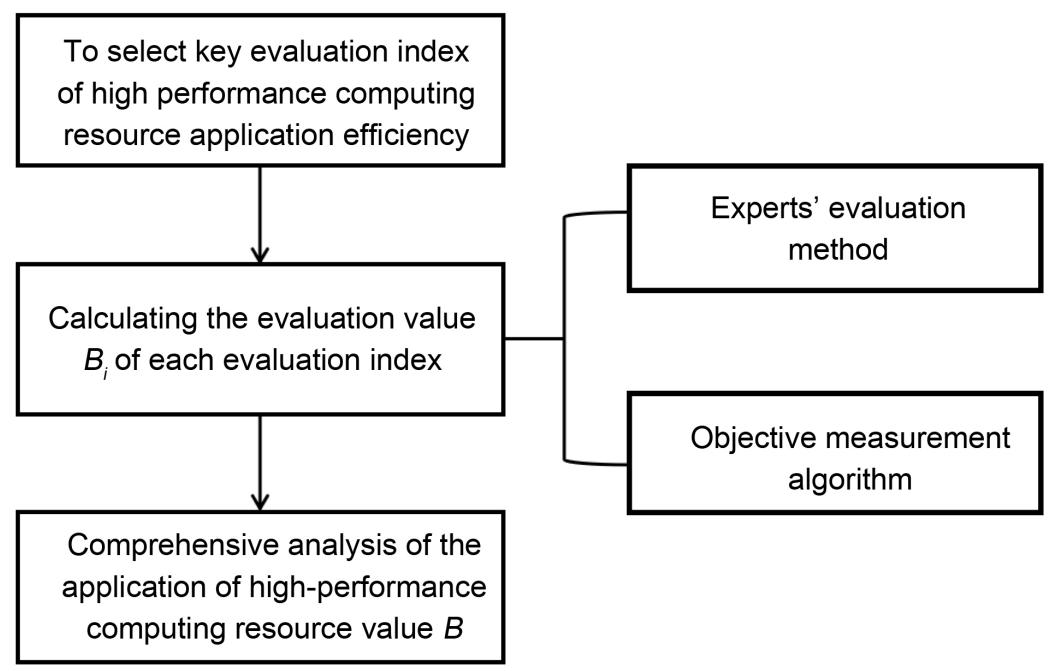

Figure 1. Evaluation process. 


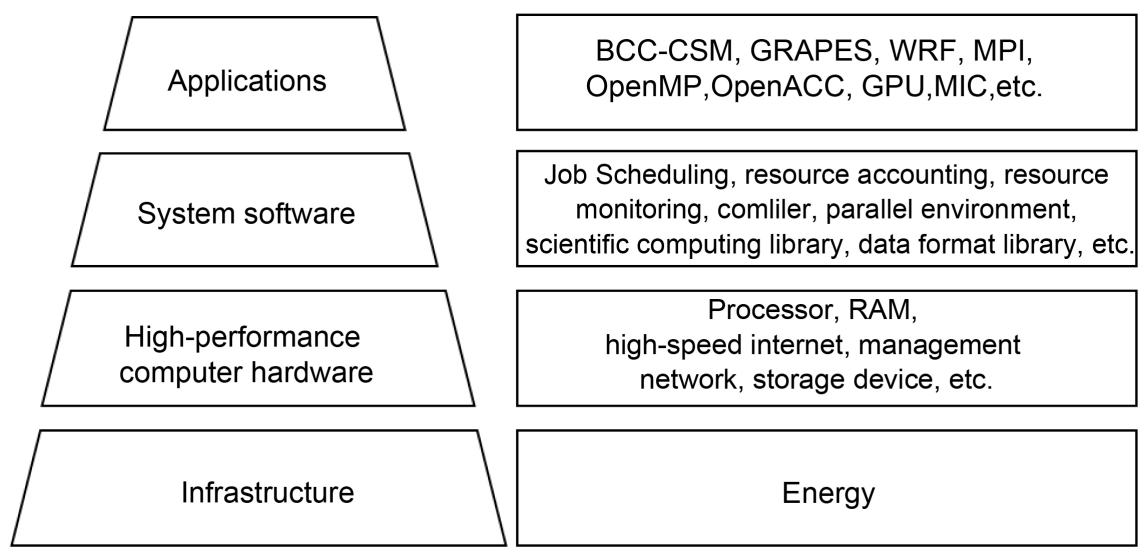

Figure 2. The level of computing resources.

benefits, model computation benefits and application benefits, benefits assessment (the "overall use of satisfaction assessment index"), evaluation of the effectiveness of resource use, model evaluation and evaluation of the effectiveness of the application of industry evaluation indicators. According to the characteristics of each class of secondary indexes, a three-level indicator is established, which can reflect the actual use situation. According to the importance of the two, three indicators, we set different weights, and the same level within the sum of the weights of the indicators equals 1 . At different stages of development, we can adjust the content and weight of the secondary and tertiary indicators. Assessment indicators are divided into two types of subjective assessment and objective assessment. The first level indicator contains many secondary level indicators, and the secondary indicators contain many third-level indicators. As shown in Table 1.

\subsection{Evaluation Method}

The benefit value B of meteorological high performance computing resource is calculated by the benefit value of each secondary index, and the benefit value of each secondary index is calculated from the value of the third-class index. The indicators at different levels represent different aspects of the use of high-performance computing resources. In order to form a quantitative and comprehensive assessment of the use of resources, setting a total score $S_{l 3}$ for each of the three indicators, the three indicators of the actual compliance rate is $E_{l 3}$, then the value of the three indicators is $B_{l 3}=S_{l 3} \times E_{l 3}$.

The benefits of each secondary index were evaluated synthetically by linearweighted summation method. Assume a secondary index contains third level indicators a total of $\mathrm{n}$ can be expressed as $I_{l 3}=\left\{I_{l 31}, I_{l 32}, \cdots, I_{l 3 n}\right\}$. The weight set corresponding to each three-level index can be expressed as $W_{l 3}=\left\{W_{l 31}, W_{l 32}, \cdots, W_{l 3 n}\right\}$. The corresponding benefit value is $B_{l 3}=\left\{B_{l 31}, B_{l 32}, \cdots, B_{l 3 n}\right\}$. Then the value of the secondary indicators is $B_{l 2}=\sum_{i}^{n} B_{l 3 i} \times W_{l 3 i}$, where $0 \leq W_{l 3 i} \leq 1, \quad \sum_{i}^{n} W_{l 3 i}=1(i=1,2, \cdots, n)$.

Similarly, using the linear-weighted summation method assesses $B$ value of 
Table 1. The application benefit evaluation index of high-performance computing resource.

\begin{tabular}{ccc}
\hline $\begin{array}{c}\text { First level } \\
\text { indicator }\end{array}$ & Secondary level indicator (weight) & Third level indicator (weight) \\
\hline & Overall service satisfaction (10\%) & Satisfaction (100\%) \\
& Resource usage benefits (30\%) & $\begin{array}{c}\text { Occupancy rate (40\%) } \\
\text { Convenience (20\%) }\end{array}$ \\
$\begin{array}{c}\text { Application } \\
\text { benefit of high } \\
\text { performance } \\
\text { computing } \\
\text { resources }\end{array}$ & Model computational benefits (30\%) & Computational efficiency (60\%) \\
& Application benefits (20\%) & Application effect (100\%) \\
& Infrastructure benefits (10\%) & Energy consumption output \\
& & $(100 \%)$ \\
\hline
\end{tabular}

the use resources of high-performance computing resources comprehensively. Contains secondary indicators in total of $\mathrm{n}$, can be expressed as $I_{l 2}=\left\{I_{l 21}, I_{l 22}, \cdots, I_{l 2 n}\right\}$. The corresponding weight set can be expressed as $W_{l 2}=\left\{W_{l 21}, W_{l 22}, \cdots, W_{l 2 n}\right\}$. And the corresponding benefit value is $B_{l 2}=\left\{B_{l 21}, B_{l 22}, \cdots, B_{l 2 n}\right\}$. Then the high-performance computing resource application benefit value is $B=\sum_{i}^{n} B_{l 2 i} \times W_{l 2 i}$, where $0 \leq W_{l 2 i} \leq 1$ and $\sum_{i}^{n} W_{l 2 i}=1(i=1,2, \cdots, n)$.

\section{Summary and Prospect}

The application of high performance computing resources in meteorology has achieved initial results, which can be applied to the annual analysis of the investment efficiency of meteorological high performance computing resources in China and provided reference for the construction of next generation high performance computing system. As the basic support of the numerical model, the computing resources tend to be intensified in the business layout and geographical distribution. With the construction and application of computing resources based on the unified data service environment, dynamic resource scheduling and more refined management can be realized through the resource application and management soft environment, improving the computing efficiency of the model and realizing the cooperative development in different places. By gradually perfecting the evaluation index selection and measurement method, the evaluation system will adapt to it, and make the assessment of the application of computing resources more comprehensive, objective and scientific, and the assessment results will be more in line with the actual situation. And the results of the evaluation work will be applied step by step in all phases of the life cycle of high performance computing resources. Standardization, objectivity, normalization of services is the future application of high-performance computing resources evaluation of the development trend [16]. In order to meet the growing demand for meteorological numerical model operational system for the high performance computing application service environment, we provide the application platform of numerical model stable and efficient operation, and carry out the 
construction work of meteorological high performance computing application service environment. The application requirements of the in-depth analysis plan and design the initial implementation of the construction program, including the unified application of systems and application planning, model software application framework construction and so on. The meteorological numerical model operational and scientific research works are carried out to provide a strong technical support and protection. For the optimization of the measurement method, we will conduct further research in the future.

\section{Acknowledgements}

This work was supported by China Special Fund for Meteorological Research in the Public Interest (GYHY201306062), National Key R\&D Program of China (2016YFA0602102), and National Natural Science Foundation of China (41275076).

\section{References}

[1] Wei, M., Sun, J. and Shen, Y. (2013) Performance Evaluation Method of High Performance Computing System and Its Application. Journal of Applied Meteorological Science, 24, 753-760.

[2] Wei, M., Luo, Y. and Wang, L.N. (2005) A Study on the Optimum Algorithm of Global Ocean-Atmosphere coupled Models. Journal of Applied Meteorological Science, 16, 408-412.

[3] Chen, S.R., Hu, K. and Zhang, W. (2008) Performance Monitoring and Analysis of Multi-Cluster Parallel Operation. Computer Engineering, 34, 75-77.

[4] Chen, D.H. and Shen, X.S. (2006) Research Progress of the New Generation Numerical Prediction System GRAPES. Journal of Applied Meteorological Science, 17, 773-777.

[5] Wu, X.J., Jin, Z.Y. and Huang, L.P. (2005) Framework and Implementation of GRAPES Model Software. Journal of Applied Meteorological Science, 16, 539-546.

[6] Wu, T.W., Yu, R.C. and Zhang, F. (2010) The Beijing Climate Center Atmospheric General Circulation Model: Description and Its Performance for the Present-Day Climate. Climate Dynamics, 34, 123-147. https://doi.org/10.1007/s00382-008-0487-2

[7] Wu, T.W., Li, W.P. and Ji, J.J. (2013) Global Carbon Budgets Simulated by the Beijing Climate Center Climate System Model for the Last Century. Journal of Geophysical Research, 118, 1-22.

[8] Zhang, L.C. (2011) Meteorological Information System. Vol. 252, China Meteorological Press, Beijing, 72-84.

[9] Wang, B. (2014) Application of High Performance Computing Technology in Meteorological Department. Computer Engineering and Design, 35, 1476-1479.

[10] Wang, B., Zong X. and Wei, M. (2008) A Fine-Grained, Real Time HPC Resource Management System. Journal of Applied Meteorological Science, 19, 507- 511.

[11] Wang, B., Xiao, W.M. and Li, Y.S. (2011) Establishment and Application of Computing Resource Management System in South China Regional Center. Meteorological Monthly, 37, 764-770.

[12] Wei, M. (2015) Study on Application Environment Adaptability of Meteorological High Performance Computing. Meteorological Monthly, 92-97. 
[13] Wei, M., Xu, J.X. and Wang, Z.Z. (2014) Application of Parallel I/O Technology in Climate Numerical Model. Computer Technology and Development, 24, 11-15.

[14] Xiao, W.M., Li, Y.S. and Chen, X.Y. (2008) Discussion on Key Problems in Performance Evaluation of High Performance Computing System. Computer Systems \& Applications, 115-118.

[15] Zhang, T.R., Song, S.Y. and Tian, C.Y. (2011) Study and Method of Evaluating Benefit of Industry Meteorological Service. Journal of the Meteorological Sciences, 31, 194-199.

[16] Yao, X.P., Lv, M.H. and Fan, X.Q. (2010) Present Situation and Prospect of Meteorological Service Benefit Evaluation in China. Meteorological Monthly, 36, 62-68.

Submit or recommend next manuscript to SCIRP and we will provide best service for you:

Accepting pre-submission inquiries through Email, Facebook, LinkedIn, Twitter, etc. A wide selection of journals (inclusive of 9 subjects, more than 200 journals)

Providing 24-hour high-quality service

User-friendly online submission system

Fair and swift peer-review system

Efficient typesetting and proofreading procedure

Display of the result of downloads and visits, as well as the number of cited articles

Maximum dissemination of your research work

Submit your manuscript at: http://papersubmission.scirp.org/

Or contact gep@scirp.org 